\title{
Use of modified ultrafiltration in adults undergoing coronary artery bypass grafting is associated with inflammatory modulation and less postoperative blood loss: A randomized and controlled study
}

\author{
Anali G. Torina, MS, ${ }^{a}$ Lindemberg M. Silveira-Filho, MD, PhD, ${ }^{a}$ Karlos A. S. Vilarinho, MD, MS, ${ }^{a}$ \\ Pirooz Eghtesady, MD, PhD, ${ }^{\mathrm{c}}$ Pedro P. M. Oliveira, MD, PhD, ${ }^{\mathrm{a}}$ Andrei C. Sposito, MD, PhD, ${ }^{\mathrm{b}}$ and \\ Orlando Petrucci, $\mathrm{MD}, \mathrm{PhD}^{\mathrm{a}}$
}

\begin{abstract}
Objectives: Modified ultrafiltration (MUF) has been shown to decrease the postcardiac surgery inflammatory response and to improve respiratory function and cardiac performance in pediatric patients; however, this approach has not been well established in adults. The present study hypothesized that MUF could decrease the postsurgical inflammatory response, leading to improved respiratory and cardiac function in adults undergoing coronary artery bypass grafting.
\end{abstract}

\begin{abstract}
Methods: Sixty patients undergoing coronary artery bypass grafting were randomized to the MUF or control group $(n=30$ each). MUF was performed for 15 minutes at the end of bypass. The following data were recorded at the beginning of anesthesia, end of bypass, end of experimental treatment, and 24 and 48 hours after surgery: alveolar-arterial oxygen gradient, red blood cell units transfused, chest tube drainage, hemodynamic parameters, and cytokine levels (interleukin-6, P-selectin, intercellular adhesion molecule, and soluble tumor necrosis factor receptor).
\end{abstract}

\begin{abstract}
Results: The MUF group displayed less chest tube drainage than the control group after 48 hours $(598 \pm 123$ $\mathrm{mL}$ vs $848.0 \pm 455 \mathrm{~mL} ; P=.04)$ and less red blood cell transfusions $(0.6 \pm 0.6$ units/patient vs $1.6 \pm 1.1$ units/patient; $P=.03$ ). Hematocrit level was higher in the MUF group than in the control group at the end of bypass $(37.8 \% \pm 1.1 \%$ vs $34.1 \% \pm 1.1 \% ; P<.05)$, but the levels were comparable at 48 hours. Similar values for interleukin-6 and P-selectin were observed at all stages. Plasma levels of intercellular adhesion molecule were higher in the MUF group than in the control group, particularly in the first sampling after experimental treatment $(P=.01)$. Plasma levels of soluble tumor necrosis factor receptor were higher in the MUF group than in the control group at 48 hours. Hemodynamic and oxygen transport parameters were similar in both groups throughout the observation period. There were no differences in other clinical outcomes.
\end{abstract}

Conclusions: Use of MUF was associated with increased inflammatory response, reduced blood loss, and less blood transfusions in adults undergoing coronary artery bypass grafting. (J Thorac Cardiovasc Surg 2012;144:663-70)

Despite advances in surgical techniques and technology and understanding of the pathophysiology of cardiac disease, the inflammatory response after cardiac surgery with cardiopulmonary bypass $(\mathrm{CPB})$ remains a problem, leading

\footnotetext{
From the Department of Surgery, ${ }^{\mathrm{a}}$ Discipline of Cardiac Surgery, Faculty of Medical Science, State University of Campinas, UNICAMP, Campinas, São Paulo, Brazil; Department of Internal Medicine, ${ }^{\mathrm{b}}$ Discipline of Cardiology, Faculty of Medical Science, State University of Campinas, UNICAMP, Campinas, São Paulo, Brazil; and Division of Cardiothoracic Surgery, ${ }^{\mathrm{c}}$ Children's Hospital, School of Medicine, Washington University, St Louis, Mo.

Funding: Fundação de Amparo à Pesquisa de São Paulo, São Paulo, Brazil.

Disclosures: Authors have nothing to disclose with regard to commercial support.

Received for publication Jan 11, 2012; revisions received March 21, 2012; accepted

for publication April 4, 2012; available ahead of print May 11, 2012.

Address for reprints: Orlando Petrucci, MD, PhD, Department of Surgery, Rua João

Baptista Geraldi, 135, Campinas, SP, CEP 13085020, Brazil (E-mail: petrucci@

cardiol.br or orlando@fcm.unicamp.br).

$0022-5223 / \$ 36.00$

Copyright (c) 2012 by The American Association for Thoracic Surgery

doi:10.1016/j.jtcvs.2012.04.012
}

to postoperative bleeding, pulmonary dysfunction, and increased mortality and morbidity. Several strategies have been described to minimize this response. ${ }^{1,2}$ In this context, modified ultrafiltration (MUF) has been shown to attenuate the inflammatory response, bleeding, and pulmonary dysfunction in children undergoing congenital heart surgery. ${ }^{3,4}$ From a mechanistic standpoint, MUF is associated with removal of several inflammatory mediators generated during $\mathrm{CPB} .{ }^{5}$ However, in contrast with the well-documented effects in children, use of MUF in the adult population has garnered mixed results. ${ }^{6}$

In some pathologic states, including acute myocardial infarction or reperfusion during $\mathrm{CPB}$, the plasma accumulates various stimuli that are capable of activating polymorphonuclear neutrophils (PMNs) and endothelial cells. ${ }^{7}$ Activated cells may shed their adhesion molecules into the circulating blood, where they can affect the immunologic response. Plasma levels of soluble adhesion molecules 


$$
\begin{aligned}
& \text { Abbreviations and Acronyms } \\
& \text { A-a }=\text { alveolar-arterial } \\
& \mathrm{A}-\mathrm{aDO}_{2}=\text { alveolar-arterial oxygen gradient } \\
& \mathrm{CABG}=\text { coronary artery bypass grafting } \\
& \mathrm{CPB}=\text { cardiopulmonary bypass } \\
& \mathrm{DO}_{2}=\text { oxygen delivery } \\
& \text { ICAM }=\text { intracellular adhesion molecule } \\
& \text { ICU = intensive care unit } \\
& \text { IL }=\text { interleukin } \\
& \text { INR = international normalized ratio } \\
& \text { MUF = modified ultrafiltration } \\
& \text { OI }=\text { oxygen index } \\
& \text { PMN = polymorphonuclear neutrophil } \\
& \text { PVR = pulmonary vascular resistance } \\
& \mathrm{RBC}=\text { red blood cell } \\
& \text { sICAM }=\text { soluble intracellular adhesion molecule } \\
& \text { SVR = systemic vascular resistance } \\
& \mathrm{TNF}=\text { tumor necrosis factor } \\
& \text { TNFR }=\text { tumor necrosis factor receptor } \\
& \mathrm{VO}_{2} \quad \text { oxygen consumption }
\end{aligned}
$$

could indicate the intensity of activation of PMNs and endothelial cells after CPB. ${ }^{8,9}$ In the present study, using a randomized controlled trial design, we assessed the safety of MUF and its associated inflammatory modulation through tissue markers of inflammatory activity in adult patients undergoing elective coronary artery bypass grafting (CABG) with $\mathrm{CPB}$ support.

\section{MATERIALS AND METHODS \\ Patient Selection}

Approval for this study was obtained from the Institutional Review Board for Human Research, and the trial was registered at Clinicaltrials.gov (Identifier: NCT01140113). Sixty consecutive patients undergoing elective on-pump CABG were enrolled in the study. According to the recommendations of the Declaration of Helsinki, all patients provided written informed consent before enrollment. The Consolidated Standards of Reporting Trials study flow is summarized in Figure 1.

Inclusion criteria were age between 30 and 70 years, left ventricle ejection fraction greater than $39 \%$, and glomerular filtration rate (calculated by the Cockcroft-Gault equation) greater than $45 \mathrm{~mL} / \mathrm{min} / 1.73 \mathrm{~m}^{2}$ in men or greater than $40 \mathrm{~mL} / \mathrm{min} / 1.73 \mathrm{~m}^{2}$ in women. Exclusion criterion was indication for mitral valve repair or other surgical procedure in addition to the planned CABG. All patients had discontinued aspirin or clopidogrel bisulfate therapy at 5 or 7 days, respectively, before the surgery.

\section{Study Design}

Patients were randomly assigned to the control group, which was treated by CABG only, or the MUF group, which was treated by CABG plus MUF. Neither the surgeon performing the operation nor the anesthesiologist in charge was blinded to the nature of the experimental intervention. A blinded nurse intensivist independently rated the chest tube blood loss within the first 48 hours after surgery. A red blood cell (RBC) transfusion was given in the intensive care unit (ICU) if the hemoglobin concentration decreased to less than $9.0 \mathrm{~g} / \mathrm{dL}$ at any time during hospitalization of the patient.
Because of a lack of previous studies using tissue inflammatory markers, the sample size was calculated on the basis of chest tube blood loss in the first 48 hours after surgery. A pilot study was carried out with 5 patients in each group. Sample size was calculated by using the software G*Power with $80 \%$ power and an alpha error of $5 \%$. The calculation predicted the need for 34 patients randomly divided into 2 arms to detect a mean difference of $160.0 \pm 55.0 \mathrm{~mL}$ at 48 hours. An extra 13 patients were added to each arm to improve study reliability.

\section{Surgical Procedure}

Anesthesia was induced with midazolam, atracurium besylate, and fentanyl and was maintained with a balanced anesthesia of inhalant and intravenous agents. After anesthesia was induced, patients were monitored with a continuous cardiac output catheter (Edwards Lifesciences, Irvine, Calif), invasive arterial mean pressure catheter, and urine output catheter. A planned tepid bypass $\left(32^{\circ} \mathrm{C}\right)$ was performed with a target flow of 2.4 $\mathrm{L} / \mathrm{min} / \mathrm{m}^{2}$. After CPB was established, the aorta was crossclamped and distal anastomoses were performed. Blood tepid cardioplegia was used during the crossclamp period. The clamp was released, and a C-clamp was applied for performance of the proximal anastomoses. Afterward, the patients were weaned from the bypass. In all cases, the cardiotomy suction was used as necessary. When needed to achieve optimal cardiac output, dopamine combined with sodium nitroprusside was the preferred inotrope. All operations were performed by 1 surgeon (O.P.).

\section{Modified Ultrafiltration}

MUF was performed in heparinized patients between the arterial and venous tubing of the CPB circuit. An H-500 filter (polyethersulfone) was used, which had an effective membrane area of $0.5 \mathrm{~m}^{2}$, pore size of $5 \mathrm{~nm}$, prime volume of $34 \mathrm{~mL}$, maximum transmembrane pressure of $400 \mathrm{~mm} \mathrm{Hg}$, internal fiber diameter of $200 \mu \mathrm{m}$, and fiber wall thickness of $30 \mu \mathrm{m}$ (Braile Biomedica, São José do Rio Preto, Brazil). The blood flow rate through the filter $(300 \mathrm{~mL} / \mathrm{min})$ was maintained by a roller pump on the inlet part of the filter. Suction was applied to the filtrate port to achieve a negative pressure of $100 \mathrm{~mm} \mathrm{Hg}$. The process was carried out for 15 minutes in all patients who underwent MUF. Patients assigned to the control group were instead observed for 15 minutes.

\section{Oxygen Transport and Hemodynamic Parameters}

Blood was sampled, and the indexed cardiac output, systemic vascular resistance (SVR), pulmonary vascular resistance (PVR), mean arterial pressure, oxygen delivery $\left(\mathrm{DO}_{2}\right)$, oxygen consumption $\left(\mathrm{VO}_{2}\right)$, oxygen index $(\mathrm{OI})$, and alveolar-arterial oxygen gradient $\left(\mathrm{A}-\mathrm{aDo}_{2}\right)$ were recorded just after induction of anesthesia, before and after MUF, and at 24 and 48 hours after $\mathrm{CABG}$. OI was calculated by $\mathrm{OI}=\left(\mathrm{FIO}_{2} \times \mathrm{MAP}\right) / \mathrm{PaO}_{2}$. The $\mathrm{A}-\mathrm{aDO}_{2}$ was calculated by $\mathrm{A}-\mathrm{aDo}_{2}=713 \times\left(\mathrm{FiO}_{2}-\mathrm{PaO}_{2}-\mathrm{PaCO}_{2}\right)$, where $\mathrm{FIO}_{2}$ is the inspired fraction of oxygen, MAP is the mean airway pressure, and $\mathrm{PaO}_{2}$ and $\mathrm{PaCO}_{2}$ are the partial pressures of oxygen and carbon dioxide, respectively, in the arterial blood.

Blood samples were collected from the arterial line with heparin-coated tubes. Collected samples were centrifuged for 20 minutes at $4^{\circ} \mathrm{C}$, and serum aliquots were stored at $-80^{\circ} \mathrm{C}$. Levels of interleukin (IL)-6, P-selectin, soluble intracellular adhesion molecule (sICAM) 1, and soluble tumor necrosis factor receptor (TNFR) 2 were measured with commercially available enzyme-linked immunosorbent assay kits (R\&D Systems, Abingdon, UK). Serum creatinine, international normalized ratio (INR) for prothrombin time, activated partial thromboplastin time, leukocyte count, serum lactate, and blood urea nitrogen were measured after blood collection at the hospital central laboratory.

\section{Study Outcomes}

Primary outcomes were chest tube blood loss within the first 48 hours after surgery, blood transfusion requirement (rated as the number of 


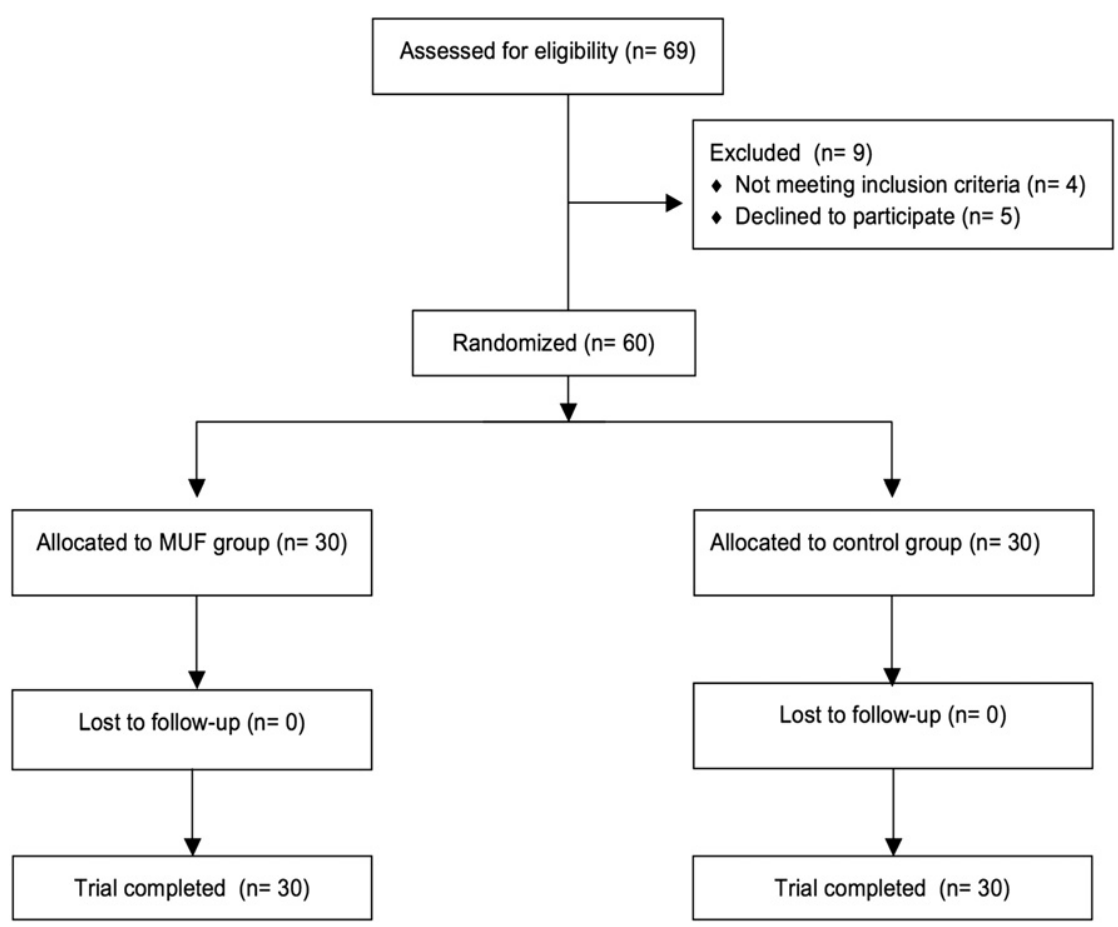

FIGURE 1. Consolidated Standards of Reporting Trials flowchart of the study. MUF, Modified ultrafiltration.

RBC units transfused before hospital discharge), ICU length of stay (days), and hospital length of stay (days). Secondary outcome was inflammatory response, which was assessed by serum levels of IL-6, soluble TNFR2, P-selectin, and sICAM-1.

\section{Statistical Analyses}

Continuous variables were expressed as means with 1 standard deviation. Categoric variables were expressed as frequencies. All data were tested for normality, and transformations were performed as necessary. The $t$ test for unpaired samples was used to analyze total bleeding volume and required units of transfused RBCs. Two-way analysis of variance was performed for intragroup, intergroup, and time/group interactions with the Bonferroni post hoc test (GraphPad Prism version 5.0 for Mac OS X; GraphPad Software Inc, San Diego, Calif).

\section{RESULTS}

\section{Demographic Data and Intraoperative Variables}

Demographic and surgical data were similar between the 2 groups, although the control group showed a lower incidence of peripheral arterial disease $(P=.03)$ (Table 1). Chest tube drainage was lower in the MUF group $(P=.04)$, which also received fewer transfusions of RBC units $(P=.03)$. No patient in either group required mediastinal reexploration for postoperative bleeding.

\section{Hemodynamic Variables and Oxygen Transport}

SVR index and $\mathrm{DO}_{2}$ decreased and $\mathrm{VO}_{2}, \mathrm{OI}$, and alveolar-arterial (A-a) gradient increased in both groups during the observation period; however, there were no differences between the MUF and control groups in these parameters (Table 2).

\section{Hematocrit, Lactate, Blood Cell Count, and Blood Clot Tests}

Results of the hematocrit, lactate, blood cell counts, and blood clot tests are summarized in Table 3. Hematocrit decreased during the observation period and was higher in the MUF group, particularly immediately after the MUF procedure $(P=.02)$. Lactate levels, leukocyte count, and INR increased in both groups compared with measurements taken immediately after anesthesia induction, but there were no differences in these parameters between the control and MUF groups.

\section{Inflammatory Mediators}

Serum IL-6 levels were elevated after induction of anesthesia in both groups. The IL-6 levels were higher in the MUF group right after ultrafiltration $(P<.05)$ and comparable at 24 and 48 hours after surgery (Figure 2, $A$ ). The P-selectin levels remained steady in both groups during the observation period compared with baseline values $(P=.79)$, and no differences were observed between the groups (Figure 2, B). At the post-MUF time point, the sICAM-1 plasma levels were increased in the MUF group and remained higher than those of the control group up to 48 hours $(P<.0001)$ (Figure 3,A). The TNFR2 levels were higher in the MUF group than in the control group at 48 hours (Figure $3, B$ ).

\section{DISCUSSION}

The current study investigated the effects of MUF in adult patients undergoing $\mathrm{CABG}$ with $\mathrm{CPB}$ support. Use 
TABLE 1. Demographics, surgical data, postoperative bleeding, intensive care unit and hospital lengths of stay, and number of red blood cell units transfused per patient

\begin{tabular}{lccr}
\hline & \multicolumn{2}{c}{ Group $(\mathbf{n}=\mathbf{3 0}$ each) } & \multicolumn{1}{c}{$\boldsymbol{P}$} \\
\cline { 2 - 3 } & MUF & Control & value \\
\hline Gender (F/M) & $20 \%(6 / 24)$ & $7 \%(2 / 28)$ & .13 \\
Age (y) & $55.2 \pm 7.3$ & $55.6 \pm 9.3$ & .84 \\
CPB time (min) & $51 \pm 10$ & $56 \pm 8$ & .06 \\
Grafts per patient* & $3(3-3)$ & $3(3-4)$ & .35 \\
Hypertension & $73 \%(22 / 8)$ & $83 \%(25 / 5)$ & .35 \\
Previous cerebral stroke & $3 \%(1 / 29)$ & $7 \%(2 / 28)$ & .55 \\
DM & $33 \%(10 / 20)$ & $27 \%(8 / 22)$ & .57 \\
Smoker & $90 \%(27 / 30)$ & $90 \%(27 / 30)$ & 1.00 \\
Ejection fraction (\%) & $60 \pm 13 \%$ & $62 \pm 8 \%$ & .69 \\
Peripheral arterial disease & $0 \%(0 / 30)$ & $20 \%(6 / 24)$ & .03 \\
Volume removal with MUF (mL) & $995 \pm 160$ & $0 \pm 0$ & $<.01$ \\
Chest tube drainage (48 h) & $645 \pm 163$ & $846 \pm 399$ & .02 \\
Fresh-frozen plasma (units) & $0.1 \pm 0.6$ & $0.2 \pm 0.8$ & .72 \\
RBC (units) & $0.7 \pm 0.7$ & $1.5 \pm 1.3$ & .01 \\
Length of stay in ICU (d) & $3.4 \pm 0.3$ & $3.5 \pm 0.3$ & .90 \\
Length of stay in hospital (d) & $5.1 \pm 0.5$ & $4.9 \pm 0.5$ & .77 \\
Statins & $63 \%(19 / 30)$ & $40 \%(12 / 30)$ & .12 \\
\hline
\end{tabular}

$M U F$, Modified ultrafiltration; $F$, female; $M$, male; $C P B$, cardiopulmonary bypass $D M$, diabetes mellitus; $R B C$, red blood cell; $I C U$, intensive care unit. *Median ( $95 \%$ confidence interval).

of MUF resulted in decreased postoperative blood loss, as indicated by decreased chest tube blood drainage and fewer RBC units transfused. Patients undergoing MUF presented hemodynamic, oxygen transport, and pulmonary parameters that were indistinguishable from those of the control group. Lactate levels, leukocyte count, activated partial thromboplastin time, and INR varied throughout the entire observation period, but no differences were detected between the 2 groups. Hematocrit was higher in the postMUF period compared with the control group, but similar between the groups at 48 hours. Similar operative mortalities and lengths of stay in the ICU and hospital were seen in the 2 groups. Most of the inflammatory markers measured, such as soluble adhesion molecules and cytokines, were increased in the MUF group compared with the control group for most of the observation period. Higher serum sICAM and TNFR2 levels were seen in the MUF group than in the control group, particularly in the post-MUF period.

These findings suggest that MUF is a relatively safe procedure for removing fluids, increasing hematocrit, and diminishing postoperative bleeding. However, MUF was not effective for ameliorating the inflammatory response or reducing the ICU and hospital lengths of stay after cardiac surgeries using CPB in the present study.

\section{Postoperative Blood Loss and Hemodynamic Parameters}

The findings presented in this article are consistent with results reported in the literature regarding the adult population after cardiac surgery using CPB with ultrafiltration. Several authors have reported decreased postoperative bleeding after use of MUF. ${ }^{10,11}$ In a meta-analysis of 11 articles, Boodhwani and colleagues ${ }^{11}$ showed favorable effects of ultrafiltration in reducing postoperative bleeding in adult patients. Six of the 11 articles had used MUF alone or in addition to conventional ultrafiltration. Kuratani and colleagues ${ }^{12}$ performed a meta-analysis of ultrafiltration use in the pediatric population. By focusing on hematocrit and blood pressure after $\mathrm{CPB}$, amount of chest tube drainage within 48 hours after surgery, time to extubation, and length of stay in the ICU, they reported higher hematocrit in the immediate postbypass period, but similar postoperative outcome parameters in the MUF and control groups. Likewise, we observed higher hematocrit levels at the end of bypass (but no difference at 48 hours), lower chest tube drainage within 48 hours of surgery, and no difference in the length of stay in the ICU or hospital in the MUF group compared with the control group.

In patients undergoing cardiac procedures with $\mathrm{CPB}$ and using a blinded anesthetist and intensivist (but an unblinded surgeon), Boodhwani and colleagues ${ }^{13}$ found that MUF was associated with an effective hemoconcentration and an increased need for vasopressor support. They did not evaluate blood chest tube drainage in the postoperative period. By using a blinded intensivist, but unblinded surgeon and anesthetist, we observed an effective hemoconcentration immediately after MUF, and patients receiving MUF required fewer RBC transfusions. The hemodynamic parameters were similar in the 2 groups.

Leyh and colleagues ${ }^{14}$ studied a small sample of patients scheduled for elective myocardial revascularization who were randomized to groups undergoing conventional ultrafiltration, MUF, or no ultrafiltration. They obtained results comparable to those of the present work, with reduced blood loss at 24 hours after surgery in the MUF group compared with the conventional ultrafiltration and no ultrafiltration groups, and similar results of routine clot tests among all 3 groups. ${ }^{14}$ Leyh and colleagues could not elucidate the mechanism(s) for reduced blood loss.

In a study of adult patients undergoing complex cardiac surgery with or without MUF, Weber and colleagues ${ }^{15}$ assessed blood loss and performed routine clot tests, multiple electrode aggregometry, and thromboelastometry. Multiple electrode aggregometry assesses general platelet aggregation, and thromboelastometry investigates intrinsic and extrinsic initiation of coagulation, plasmatic contributors to clot firmness, and heparin effects. Weber and colleagues found reduced postoperative blood loss in the MUF group compared with control, but no differences between the groups for the results of routine clot tests or thromboelastometry. However, platelet aggregation was improved in the MUF group compared with the control, which may partially explain the reduced 
TABLE 2. Hemodynamic variables and oxygen transport

\begin{tabular}{|c|c|c|c|c|c|c|c|c|c|}
\hline & Group $(n=30$ each $)$ & Induction of anesthesia & Pre-MUF & Post-MUF & $24 \mathrm{~h}$ & $48 \mathrm{~h}$ & $P^{*}$ & $\boldsymbol{P} \dagger$ & $P \ddagger$ \\
\hline \multirow[t]{2}{*}{$\mathrm{CI}\left(\mathrm{L} / \mathrm{min} / \mathrm{m}^{2}\right)$} & MUF & $3.4 \pm 0.6$ & $4.1 \pm 2.2$ & $3.2 \pm 0.7$ & $3.4 \pm 0.6$ & $3.5 \pm 0.5$ & $<.01$ & .07 & .93 \\
\hline & Control & $3.2 \pm 0.5$ & $3.1 \pm 1.3$ & $3.7 \pm 1.3$ & $3.2 \pm 0.5$ & $3.7 \pm 0.8$ & & & \\
\hline \multirow[t]{2}{*}{ SVRi (dine $/ \mathrm{s} / \mathrm{cm}^{-5} / \mathrm{m}^{-2}$ ) } & MUF & $673.9 \pm 57.5$ & $453.0 \pm 38.3$ & $635.6 \pm 48.6$ & $539.3 \pm 43.7$ & $516.3 \pm 29.9$ & .52 & $<.01$ & .79 \\
\hline & Control & $694.9 \pm 58.6$ & $551.3 \pm 58.9$ & $514.3 \pm 50.5$ & $595.4 \pm 46.6$ & $524.8 \pm 37.6$ & & & \\
\hline \multirow[t]{2}{*}{ PVRi (dine $/ \mathrm{s} / \mathrm{cm}^{-5} / \mathrm{m}^{-2}$ ) } & MUF & $62.4 \pm 6.4$ & $57.8 \pm 6.9$ & $80.2 \pm 8.6$ & $61.0 \pm 8.9$ & $52.5 \pm 6.1$ & .08 & .18 & .73 \\
\hline & Control & $69.8 \pm 9.5$ & $59.2 \pm 7.2$ & $55.7 \pm 6.9$ & $60.8 \pm 7.8$ & $56.3 \pm 5.9$ & & & \\
\hline \multirow[t]{2}{*}{$\mathrm{DO}_{2}\left(\mathrm{~mL} / \mathrm{min} / \mathrm{m}^{-2}\right)$} & MUF & $618 \pm 147$ & $478 \pm 142$ & $517.5 \pm 120$ & $405 \pm 78$ & $401 \pm 86$ & .04 & $<.01$ & .52 \\
\hline & Control & $580 \pm 101$ & $418 \pm 175$ & $550 \pm 175$ & $367 \pm 63$ & $435 \pm 115$ & & & \\
\hline \multirow[t]{2}{*}{$\mathrm{VO}_{2}\left(\mathrm{~mL} / \mathrm{min} / \mathrm{m}^{-2}\right)$} & MUF & $120 \pm 48$ & $109 \pm 46$ & $100 \pm 31$ & $153 \pm 29$ & $159 \pm 35$ & .38 & $<.01$ & .09 \\
\hline & Control & $105 \pm 27$ & $96 \pm 43$ & $81 \pm 38$ & $146 \pm 24$ & $162 \pm 45$ & & & \\
\hline \multirow[t]{2}{*}{$\mathrm{OE}(\%)$} & MUF & $0.19 \pm 0.01$ & $0.25 \pm 0.02$ & $0.20 \pm 0.01$ & $0.39 \pm 0.02$ & $0.40 \pm 0.02$ & .29 & .01 & .32 \\
\hline & Control & $0.19 \pm 0.01$ & $0.24 \pm 0.02$ & $0.15 \pm 0.01$ & $0.40 \pm 0.02$ & $0.38 \pm 0.02$ & & & \\
\hline \multirow[t]{2}{*}{$\mathrm{OI}$} & MUF & $0.40 \pm 0.03$ & $0.60 \pm 0.06$ & $0.43 \pm 0.05$ & $0.60 \pm 0.06$ & $0.59 \pm 0.06$ & .51 & $<.01$ & .43 \\
\hline & Control & $0.39 \pm 0.04$ & $0.70 \pm 0.11$ & $0.43 \pm 0.05$ & $0.67 \pm 0.09$ & $0.59 \pm 0.07$ & & & \\
\hline \multirow[t]{2}{*}{ A-a difference } & MUF & $172 \pm 24$ & $342 \pm 19$ & $278 \pm 18$ & $124 \pm 21$ & $121 \pm 18$ & .95 & $<.01$ & .77 \\
\hline & Control & $166 \pm 28$ & $358 \pm 27$ & $281 \pm 26$ & $145 \pm 19$ & $118 \pm 21$ & & & \\
\hline
\end{tabular}

$M U F$, Modified ultrafiltration; $\mathrm{CI}$, cardiac index; $\mathrm{SVRi}$, systemic vascular resistance index; $\mathrm{PVRi}$, pulmonary vascular resistance index; $\mathrm{DO}_{2}$, oxygen delivery; $\mathrm{VO}_{2}$, oxygen uptake; $O E$, oxygen extraction; $O I$, oxygenation index; $A-a$, alveolar-arterial. *Interaction between group and time. $\dagger$ Effect over time. $\ddagger$ Intergroup effect by 2 -way analysis of variance.

postoperative blood loss observed in their work and in the current study.

Boga and colleagues ${ }^{16}$ studied adult patients undergoing CABG with MUF performed 10 to 15 minutes after CPB. Higher SVR, cardiac output, and PVR were observed at the end of the surgery in the hemofiltered group. However, after 48 hours, these parameters were decreased compared with baseline, with no difference between the hemofiltered and control groups. In the present study, similar SVR, CI, and PVR results were seen in both groups at all time periods, and these values were decreased after 48 hours. Because we used different time points than Boga and colleagues to assess CI, PVR, cardiac output, and SVR, it may not be possible to compare the results immediately after MUF. However, at 20 hours after surgery, Boga and colleagues observed equivalent CI, SVR index, PVR index, $\mathrm{DO}_{2}$, and $\mathrm{VO}_{2}$ values in both groups, similar to our findings.

By examining the relationship among $\mathrm{DO}_{2}, \mathrm{VO}_{2}$, and cytokine secretion in a pediatric population with MUF, Li and colleagues ${ }^{17}$ found a decrease in $\mathrm{VO}_{2}$ after $\mathrm{CPB}$ throughout a 12-hour period, as well as a correlation between IL-8 and tumor necrosis factor (TNF) levels. However, Li and colleagues did not use a control group. In the present study, $\mathrm{VO}_{2}$ was increased in both groups, and there was no correlation between cytokine secretion and $\mathrm{VO}_{2}$. Moreover, MUF showed no deleterious or beneficial effects on $\mathrm{VO}_{2}$ or $\mathrm{DO}_{2}$ compared with the control. Although OI increased during the observation period, no difference in this index was seen between the groups.

TABLE 3. Hematocrit, lactate, blood cell count, and blood clot tests

\begin{tabular}{|c|c|c|c|c|c|c|c|c|c|}
\hline & Group $(n=30$ each $)$ & Induction of anesthesia & Pre-MUF & Post-MUF & $24 \mathrm{~h}$ & $48 \mathrm{~h}$ & $P^{*}$ & $\boldsymbol{P} \dagger$ & $P \ddagger$ \\
\hline \multirow[t]{2}{*}{ Hematocrit $(\%)$} & MUF & $41.4 \pm 4.7$ & $31.5 \pm 4.0$ & $37.9 \pm 4.8$ & $28.8 \pm 3.1$ & $28.5 \pm 3.1$ & .04 & $<.01$ & .31 \\
\hline & Control & $41.7 \pm 3.7$ & $31.8 \pm 4.1$ & $34.3 \pm 4.7$ & $28.3 \pm 4.7$ & $28.4 \pm 2.7$ & & & \\
\hline \multirow[t]{2}{*}{ Lactate (mmol/L) } & MUF & $1.1 \pm 0.5$ & $2.9 \pm 1.3$ & $2.7 \pm 1.3$ & $2.5 \pm 1.1$ & $2.3 \pm 0.6$ & .84 & $<.01$ & .50 \\
\hline & Control & $1.2 \pm 0.2$ & $2.8 \pm 1.5$ & $2.6 \pm 1.5$ & $3.1 \pm 1.0$ & $2.4 \pm 1.2$ & & & \\
\hline \multirow[t]{2}{*}{ Platelets $\left(10^{9} / \mathrm{L}\right)$} & MUF & $231.0 \pm 18.0$ & & & $149.9 \pm 10.9$ & $102.1 \pm 9.1$ & .44 & $<.01$ & .66 \\
\hline & Control & $211.5 \pm 1.4$ & & & $145.2 \pm 1.1$ & $105.9 \pm 5.7$ & & & \\
\hline \multirow[t]{2}{*}{ Leucocytes $\left(10^{9} / \mathrm{L}\right)$} & MUF & $9.0 \pm 0.8$ & & & $19.8 \pm 1.3$ & $19.8 \pm 2.9$ & .29 & $<.01$ & .79 \\
\hline & Control & $10.6 \pm 1.8$ & & & $16.7 \pm 1.3$ & $19.9 \pm 1.7$ & & & \\
\hline \multirow[t]{2}{*}{ Creatinine (mg/dL) } & MUF & $0.98 \pm 0.03$ & & & $1.09 \pm 0.10$ & $0.90 \pm 0.20$ & .94 & $<.01$ & .91 \\
\hline & Control & $0.99 \pm 0.07$ & & & $1.12 \pm 0.08$ & $0.87 \pm 0.08$ & & & \\
\hline \multirow[t]{2}{*}{ aPTT } & MUF & $1.12 \pm 0.13$ & & & $1.14 \pm 0.12$ & $1.18 \pm 0.31$ & .70 & .44 & .20 \\
\hline & Control & $1.16 \pm 0.15$ & & & $1.23 \pm 0.18$ & $1.19 \pm 0.14$ & & & \\
\hline \multirow[t]{2}{*}{ INR for prothrombin time } & MUF & $1.13 \pm 0.03$ & & & $1.14 \pm 0.03$ & $1.16 \pm 0.07$ & .13 & $<.01$ & .31 \\
\hline & Control & $1.16 \pm 0.04$ & & & $1.17 \pm 0.04$ & $1.14 \pm 0.03$ & & & \\
\hline
\end{tabular}

$M U F$, Modified ultrafiltration; $a P T T$, activated partial thromboplastin time; INR, international normalized ratio. *Interaction between group and time. $\dagger$ Effect over time. †Intergroup effect by 2-way analysis of variance. 


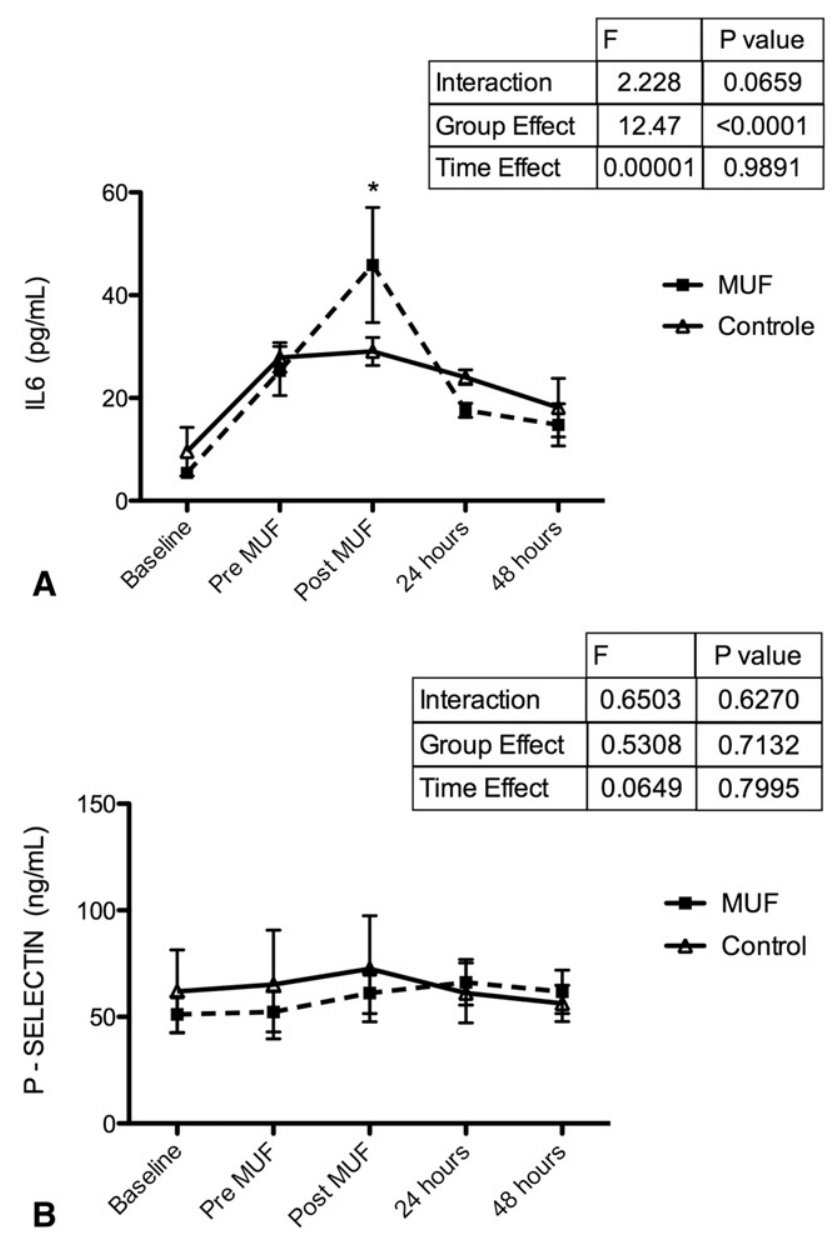

FIGURE 2. Plasma concentrations of (A) IL-6 and (B) P-selectin in the control and MUF groups. Values represent means and standard errors of the mean. $* P<.05$ by 2 -way analysis of variance with Bonferroni multiple comparisons post hoc test. IL, Interleukin; $M U F$, modified ultrafiltration.

By using MUF and control groups, Chew and colleagues ${ }^{4}$ performed a randomized prospective study of pediatric patients. They observed a slight improvement in OI, but no differences in mechanical ventilation time or A-a gradient, in the MUF group. Our findings for the A-a gradient were similar to those of Chew and colleagues, initially increasing after surgery before returning to baseline values at 48 hours. No differences were seen between the MUF and control groups. ${ }^{4}$

\section{Effect of Ultrafiltration on Levels of Plasma Inflammatory Mediators}

Most studies of MUF use in adults have estimated the inflammatory response through plasma levels of mediators, such as TNF and IL-6. TNF may play an important role in inflammation after cardiac surgery by binding to its receptors, TNFR1 or TNFR2, the latter of which is associated with cardiac and renal functional impairment in patients with coronary artery disease. ${ }^{18}$ Similar serum expression

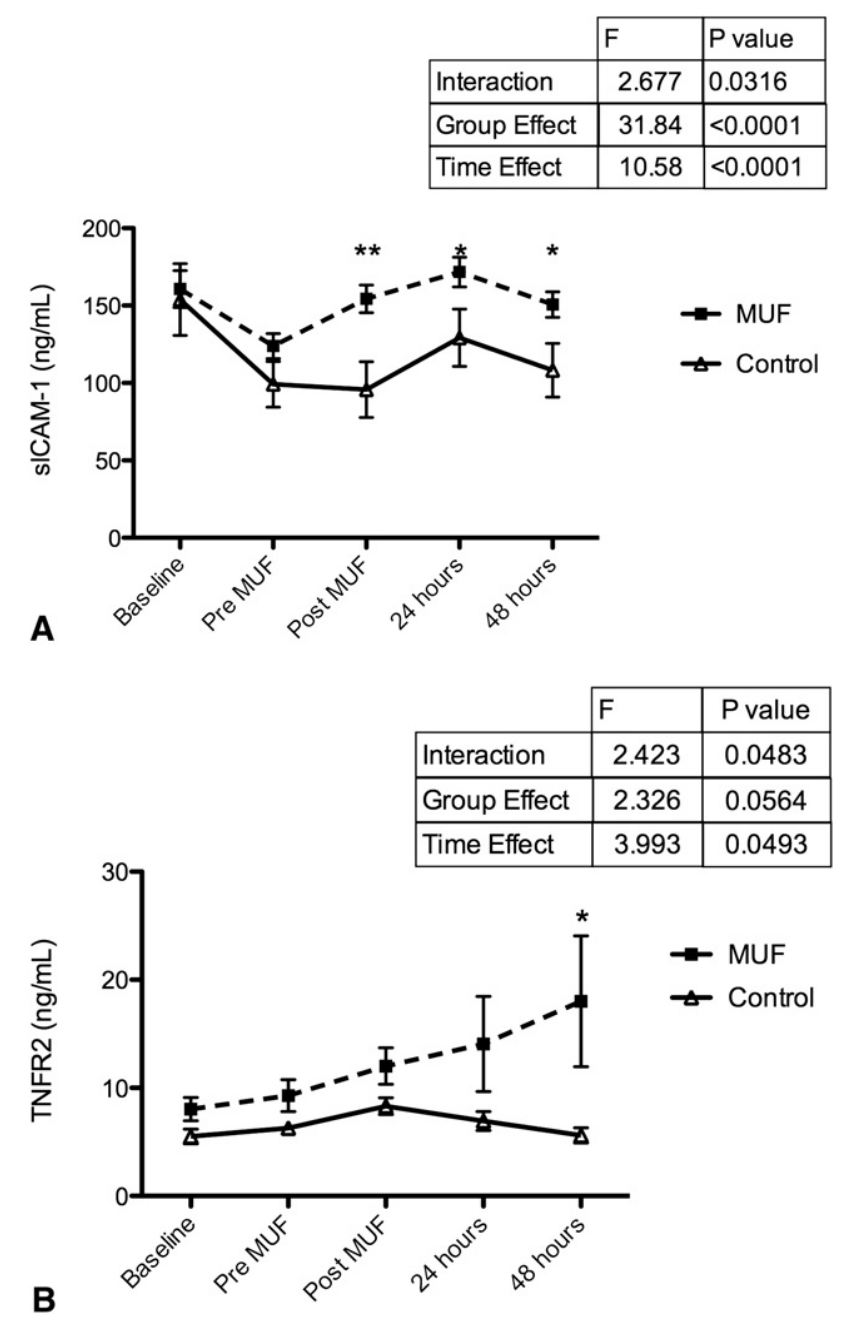

FIGURE 3. Plasma concentrations of (A) sICAM-1 and (B) TNFR2 in the control and MUF groups. Values represent means and standard errors of the mean. $* P<.01$ and $* * P<.001$ by 2 -way analysis of variance with Bonferroni multiple comparison post hoc test. $M U F$, Modified ultrafiltration; TNFR2, tumor necrosis factor receptor 2; sICAM-1, soluble intracellular adhesion molecule 1 .

levels of TNF are found in patients with heart failure with reduced or preserved ejection fraction. Increased serum TNFR2 expression in patients with heart failure and preserved ejection fraction is associated with a poor prognosis and heart failure progression. ${ }^{19}$ However, serum expression levels of TNF and IL-6 may not reflect the tissue inflammatory response, and their use may explain the observed contradictions between studies. ${ }^{6}$

Activation of PMNs and endothelial cells, which play prominent roles in the inflammatory response after $\mathrm{CPB},{ }^{20}$ initiates a cascade of cell-cell interactions that amplify the inflammatory response. These interactions require the expression of specific adhesion proteins on the cell surface, which include well-known markers of cell activation, such as soluble L-selectin (expressed by neutrophils), 
P-selectin (expressed by platelets and endothelial cells), ${ }^{7}$ and intracellular adhesion molecule (ICAM) 1. Selectin proteins establish a first step in the cascade of immunologic interactions between endothelial and immunocompetent cells, mediating the initial adhesion and rolling of leukocytes on endothelial surfaces. ${ }^{7}$ Although increased plasma levels of P-selectin are unlikely to indicate platelet dysfunction, it remains unclear whether they reflect endothelial dysfunction or platelet activation. ${ }^{7}$ An immunoglobulin gene superfamily member, ICAM-1 mediates leukocyte adhesion and transmigration through the endothelium. Elevated ICAM-1 levels are found in tissues affected with malignancies, inflammatory diseases, and ischemia. ${ }^{21}$ After proteolytic cleavage of the ICAM-1 molecule, soluble ectodomain is released from the cell surface and may modulate inflammation by binding to leukocyte integrins. ${ }^{21}$

In several reports, MUF has been shown to improve clinical function by removing inflammatory mediators, such as the cytokines and soluble adhesion molecules. ${ }^{6}$ However, it is not known whether a reduction in inflammatory mediators actually reduces the patient inflammatory process after CPB or whether any type of ultrafiltration is capable of ameliorating the inflammatory response after CPB. By applying a similar filter as used in the present study, we previously showed that the efficient removal of inflammatory mediators from conventionally hemofiltered fluid had no clear clinical benefit when performed during CABG in adults. ${ }^{22}$ Tallman and colleagues ${ }^{23}$ found that use of zero-balance ultrafiltration in patients undergoing CABG had no clear clinical benefit, although it was capable of removing significant amounts of proinflammatory mediators (eg, IL-6, IL-1, and TNF). These findings are similar to those of the present study in terms of clinical variables, such as ICU and hospital lengths of stay.

We observed higher serum levels of IL-6 immediately after MUF compared with the control group. However, at 24 and 48 hours, the IL-6 levels were comparable between groups, as reported by others. ${ }^{6,22,24}$ Although we observed an increase in TNFR2 expression in the MUF group, which may indicate a worsening of the inflammatory response, we did not observe any negative clinical outcome (ie, renal or cardiac dysfunction) related to this finding. Unfortunately, we cannot explain the biological importance of this observation. Steady P-selectin levels were seen throughout the observation period in both groups, suggesting that MUF adds little further injury to the platelets in addition to what has occurred as a result of bypass. The observed constant P-selectin level might corroborate the improvement of platelet aggregation after MUF reported by Weber and colleagues. ${ }^{15}$

Grunenfelder and colleagues ${ }^{6}$ compared patients undergoing normothermic or hypothermic CPB with MUF. They found decreased ICAM and E-selectin levels after MUF, particularly after hypothermic CPB. In the present study, all patients underwent normothermic CPB, and the hemofilter used was similar to that used by Grunenfelder and colleagues, although with a higher surface area $(0.5$ vs $0.2 \mathrm{~m}^{2}$ ). We observed that serum ICAM expression was higher in the MUF group than in the control group. The MUF group experienced more blood contact with foreign structures, such as nonendothelial surfaces and hemofilter fibers. The increased contact may have increased endothelial activation, as described in patients using left ventricular assist devices, ${ }^{25}$ which was evidenced by the elevated ICAM serum levels. Despite such differences in the ICAM serum levels, the clinical variables were similar between the groups and to those of Grunenfelder and colleagues ${ }^{6}$ after MUF.

Overall, the results of the current study and previous studies suggest that removal of inflammatory mediators with any type of hemofiltration does not necessarily reduce all inflammation in a patient after CPB. In this regard, other strategies for reducing the inflammatory response after $\mathrm{CPB}$, such as through the use of statins and angiotensinconverting enzyme inhibitors, may be more efficient than hemofiltration. ${ }^{1}$

\section{Study Limitations}

Our study was limited by the sample size, although we were able to show a significant decrease in postoperative bleeding and an increase in ICAM and TNFR2 serum levels after MUF.

The surgeon and anesthesiologist were not blinded for group selection, but all measurements (ie, chest tube drainage, inflammatory markers, hematocrit, transfusion decisions) were performed in a blinded manner. The study was not designed to evaluate mortality, ICU stay, or hospital length of stay.

We did not measure the inflammatory mediators in the removed hemofiltered fluid. However, the pore size, transmembrane pressure, and filter area used should be sufficient for the efficient removal of inflammatory mediators, according to previous studies. ${ }^{6,24}$

\section{CONCLUSIONS}

MUF is a safe procedure for intraoperative fluid management that is able to reduce postoperative bleeding and the need for RBC transfusion. However, MUF is not capable of reducing the inflammatory response and shows no clinical beneficial effects after CPB in adult patients undergoing CABG.

\section{References}

1. Radaelli A, Loardi C, Cazzaniga M, Balestri G, DeCarlini C, Cerrito MG, et al. Inflammatory activation during coronary artery surgery and its dose-dependent modulation by statin/ACE-inhibitor combination. Arterioscler Thromb Vasc Biol. 2007;27:2750-5.

2. Sobieski MA 2nd, Graham JD, Pappas PS, Tatooles AJ, Slaughter MS. Reducing the effects of the systemic inflammatory response to cardiopulmonary bypass: 
can single dose steroids blunt systemic inflammatory response syndrome? ASAIO J. 2008;54:203-6.

3. Raja SG, Dreyfus GD. Modulation of systemic inflammatory response after cardiac surgery. Asian Cardiovasc Thorac Ann. 2005;13:382-95.

4. Chew MS, Brix-Christensen V, Ravn HB, Brandslund I, Ditlevsen E, Pedersen J, et al. Effect of modified ultrafiltration on the inflammatory response in paediatric open-heart surgery: a prospective, randomized study. Perfusion. 2002;17:327-33.

5. Berdat PA, Eichenberger E, Ebell J, Pfammatter JP, Pavlovic M, Zobrist C, et al. Elimination of proinflammatory cytokines in pediatric cardiac surgery: analysis of ultrafiltration method and filter type. J Thorac Cardiovasc Surg. 2004;127:1688-96.

6. Grunenfelder J, Zund G, Schoeberlein A, Maly FE, Schurr U, Guntli S, et al. Modified ultrafiltration lowers adhesion molecule and cytokine levels after cardiopulmonary bypass without clinical relevance in adults. Eur J Cardiothorac Surg. 2000;17:77-83.

7. Chen MC, Chang HW, Juang SS, Yip HK, Wu CJ. Increased plasma levels of soluble P-selectin in rheumatic mitral stenosis. Chest. 2004;126:54-8.

8. Wei M, Kuukasjarvi P, Laurikka J, Pehkonen E, Kaukinen S, Laine S, et al. Inflammatory cytokines and soluble receptors after coronary artery bypass grafting. Cytokine. 2001;15:223-8.

9. Koga H, Kobayashi H, Yamataka A, Lane GJ, Miyano T. Intercellular adhesion molecule (ICAM-1) response after major neonatal surgery. Pediatr Surg Int. 2005;21:695-700.

10. Steffens TG, Kohmoto T, Edwards N, Wolman RL, Holt DW. Effects of modified ultrafiltration on coagulation as measured by the thromboelastograph. $J$ Extra Corpor Technol. 2008;40:229-33.

11. Boodhwani M, Williams K, Babaev A, Gill G, Saleem N, Rubens FD. Ultrafiltration reduces blood transfusions following cardiac surgery: a meta-analysis. Eur J Cardiothorac Surg. 2006;30:892-7.

12. Kuratani N, Bunsangjaroen P, Srimueang T, Masaki E, Suzuki T, Katogi T. Modified versus conventional ultrafiltration in pediatric cardiac surgery: a metaanalysis of randomized controlled trials comparing clinical outcome parameters. J Thorac Cardiovasc Surg. 2011;142:861-7.

13. Boodhwani M, Hamilton A, de Varennes B, Mesana T, Williams K, Wells GA, et al. A multicenter randomized controlled trial to assess the feasibility of testing modified ultrafiltration as a blood conservation technology in cardiac surgery. J Thorac Cardiovasc Surg. 2010;139:701-6.

14. Leyh RG, Bartels C, Joubert-Hubner E, Bechtel JF, Sievers HH. Influence of modified ultrafiltration on coagulation, fibrinolysis and blood loss in adult cardiac surgery. Eur J Cardiothorac Surg. 2001;19:145-51.
15. Weber CF, Jambor C, Strasser C, Moritz A, Papadopoulos N, Zacharowski K, et al. Normovolemic modified ultrafiltration is associated with better preserved platelet function and less postoperative blood loss in patients undergoing complex cardiac surgery: a randomized and controlled study. J Thorac Cardiovasc Surg. 2011;141:1298-304.

16. Boga M, Islamoglu, Badak I, Cikirikcioglu M, Bakalim T, Yagdi T, et al. The effects of modified hemofiltration on inflammatory mediators and cardiac performance in coronary artery bypass grafting. Perfusion. 2000;15:143-50.

17. Li J, Hoschtitzky A, Allen ML, Elliott MJ, Redington AN. An analysis of oxygen consumption and oxygen delivery in euthermic infants after cardiopulmonary bypass with modified ultrafiltration. Ann Thorac Surg. 2004;78: 1389-96.

18. Safranow K, Dziedziejko V, Rzeuski R, Czyzycka E, Wojtarowicz A, BinczakKuleta A, et al. Plasma concentrations of TNF-alpha and its soluble receptors sTNFR1 and sTNFR2 in patients with coronary artery disease. Tissue Antigens. 2009;74:386-92.

19. Niethammer M, Sieber M, von Haehling S, Anker SD, Munzel T, Horstick G, et al. Inflammatory pathways in patients with heart failure and preserved ejection fraction. Int J Cardiol. 2008;129:111-7.

20. Rasmussen BS, Sollid J, Knudsen L, Christensen T, Toft E, Tonnesen E. The release of systemic inflammatory mediators is independent of cardiopulmonary bypass temperature. J Cardiothorac Vasc Anesth. 2007;21:191-6.

21. Tsakadze NL, Sen U, Zhao Z, Sithu SD, English WR, D'Souza SE. Signals mediating cleavage of intercellular adhesion molecule-1. Am J Physiol Cell Physiol. 2004;287:C55-63

22. Antunes N, Dragosavc D, Petrucci Junior O, Oliveira PP, Kosour C, Blotta MH, et al. The use of ultrafiltration for inflammatory mediators removal during cardiopulmonary bypass in coronary artery bypass graft surgery. Rev Bras Cir Cardiovasc. 2008;23:175-82.

23. Tallman RD, Dumond M, Brown D. Inflammatory mediator removal by zerobalance ultrafiltration during cardiopulmonary bypass. Perfusion. 2002;17: 111-5.

24. Grunenfelder J, Zund G, Schoeberlein A, Schmid ER, Schurr U, Frisullo R, et al. Expression of adhesion molecules and cytokines after coronary artery bypass grafting during normothermic and hypothermic cardiac arrest. Eur J Cardiothorac Surg. 2000;17:723-8.

25. John R, Panch S, Hrabe J, Wei P, Solovey A, Joyce L, et al. Activation of endothelial and coagulation systems in left ventricular assist device recipients. Ann Thorac Surg. 2009;88:1171-9. 